Factors that influence the maintenance and improvement of OHSAS 18001 in adopting companies : A qualitative study

\title{
Ghahramani, Abolfazl
}

2016-11-20

Ghahramani , A 2016 , ' Factors that influence the maintenance and improvement of OHSAS 18001 in adopting companies : A qualitative study ' , Journal of Cleaner Production, vol. 137 , pp. 283-290 . https://doi.org/10.1016/j.jclepro.2016.07.087

http://hdl.handle.net/10138/233212

https://doi.org/10.1016/j.jclepro.2016.07.087

publishedVersion

Downloaded from Helda, University of Helsinki institutional repository.

This is an electronic reprint of the original article.

This reprint may differ from the original in pagination and typographic detail.

Please cite the original version. 


\title{
Factors that influence the maintenance and improvement of OHSAS 18001 in adopting companies: A qualitative study
}

\author{
Abolfazl Ghahramani ${ }^{\text {a, b, * }}$ \\ a Institute of Behavioral Sciences, University of Helsinki, Helsinki, Finland \\ ${ }^{\mathrm{b}}$ Department of Occupational Health Engineering, School of Public Heath, Urmia University of Medical Sciences, Urmia, Iran
}

\section{A R T I C L E I N F O}

\section{Article history:}

Received 16 November 2015

Received in revised form

5 July 2016

Accepted 15 July 2016

Available online 18 July 2016

\section{Keywords:}

Management commitment

Employee involvement

Safety culture

Auditing

Facilitators

Barriers

\begin{abstract}
A B S T R A C T
Many organizations are adapting to the requirements of occupational health and safety management systems worldwide. Despite the considerable acceptance of the systems for managing occupational health and safety in organizations, there is still no clear consensus on their effectiveness. The present study aimed to identify potential areas for improvements based on the experience and perception of the managers who worked in companies that are adopting the occupational health and safety assessment series 18001 standard in Iran. Sixteen semi-structured interviews were conducted with the managers. A qualitative study design using a grounded theory approach was used to analyze the gathered data. Eleven categories emerged to explain the influencing factors that hinder or facilitate the effectiveness of the standard in the companies: (1) management commitment; (2) safety communication; (3) employee involvement; (4) integration; (5) training; (6) safety culture; (7) internal incentives; (8) enforcement; (9) occupational health and safety authority' support, (10) auditing, and (11) external incentives. Moreover, a conceptual model was developed based on the categories. The commitment of the senior managers to safety and their support of the system in practice can facilitate the improvement of the adaptation to the standard in the companies. Conducting efforts to train employees about occupational health and safety and to involve them in the practices required by the standard can help the companies in creating a positive safety culture. The development of a new inspection program with more enforcement on occupational health and safety legislation by the authorities would help the companies to adopt the requirements of the legislation. The application of an enforced policy by accreditation bodies to check the third-party auditing process could also increase the quality of auditing and help to improve the effectiveness of their systems to achieve a better occupational health and safety performance.
\end{abstract}

() 2016 Elsevier Ltd. All rights reserved.

\section{Introduction}

The number of organizations that are adapting to the requirements of Occupational Health and Safety Management Systems (OHSMS) has considerably increased worldwide in recent decades. These enterprises used OHSMSs due to the presumed positive effects of the systems on the performance of Occupational Health and Safety (OHS) (Fernández-Muñiz et al., 2009; Frick, 2011). The Occupational Health and Safety Assessment Series (OHSAS) 18001 standard is a well-known OHSMS and has gained considerable acceptance worldwide since its publication in 1999 (Chang and Liang, 2009). Although a large number of organizations are adopting the requirements of OHSMSs, there is still no clear

\footnotetext{
* Institute of Behavioral Sciences, Helsinki University, Finland.

E-mail address: Abolfazl.Ghahramani@helsinki.fi.
}

consensus on their effectiveness (Goh and Chua, 2013).

Prior studies have found that the commitment of all levels of an organization, especially top management (BSI, 2007; Gallagher, 2000; LaMontagne et al., 2004), management promises and support (Chen et al., 2009), employee involvement (LaMontagne et al., 2004), and OHS training and communication (Fernández-Muñiz et al., 2009, 2012a; Gallagher, 2000) can influence the effectiveness of an OHSMS. The degree of an OHSMS implementation, the features of the interested enterprises, the maintenance of the system, the features of the employed OHSMS, financial resources, the number of employees available to perform OHS activities, and the external environment were found to be the other important factors that can impact the success of an OHSMS (Bluff, 2003; Robson et al., 2007). Furthermore, the national regulations and authority handling, non-governmental safety standards, and national economic wealth and culture have been identified as external influencing factors on the safety performance of organizations (Kjellén, 2012). 
Other studies have mainly discussed the role of an OHSMS and safety culture/climate in ensuring the safety in organizations (Fernández-Muñiz et al., 2012b; Gill and Shergill, 2004). Lai et al. (2011) reviewed the main constructs of the safety culture, including safety training, communication and feedback, employee participation, and management commitment to safety. They considered these constructs as practices of human resources that can positively influence the outcomes of an organization. Vinodkumar and Bhasi (2011) found that OHSAS 18001-certified companies had the highest level of management commitment; safety training; workers' involvement; safety communication and feedback; safety rules and procedures, and safety promotion policies compared with organizations with ISO 9001 certification or non-certified companies.

Managers' commitment to safety must be demonstrated in their words and observable in their actions in an organization (Hofmann et al., 1995). Top managers should prove their commitment to safety through active involvement in safety inspections, by encouraging and reminding workers to do their job safely, and financially supporting safety programs (Lai et al., 2011). This kind of commitment can be considered as a major factor for the success and sustainability of safety interventions, and it can effectively reduce injuries and illnesses in a workplace (Lai et al., 2011; Zohar and Luria, 2003).

Employee participation in safety practices is a decisive factor in safety management. Employees who are closely involved with the work should be empowered as the most qualified people to engage in organizations' decision-making and make suggestions for safety improvements (Lai et al., 2011; Vredenburgh, 2002). Incentives such as rewards can influence employee involvement in OHS activities and promote safe behaviors in an organization (FernándezMuñiz et al., 2007).

In addition, safety training and communication are other important factors that could influence the effectiveness of an OHSMS. Safety training helps employees to improve their knowledge, skills, and abilities to safely perform their jobs. It can also lead to an increase in the knowledge of employees that they have enough information about the importance of safety in their jobs and even mitigate accidents in the workplace (Lai et al., 2011). A proper safety communication between managers and employees is a significant safety management practice that positively influences the safety performance of organizations (Fernández-Muñiz et al., 2012b; Vinodkumar and Bhasi, 2011). Zachariassen and Knudsen (2002) identified promotion in the transfer of OHS knowledge, the description of employees' OHS responsibilities, and active involvement of employees in OHS practices as positive results of the integration of OHS risk management into organizational practices and frameworks.

Few studies have been conducted on the effectiveness of OHSMSs, especially the effect of OHSAS 18001 on safety performance (Robson et al., 2007; Vinodkumar and Bhasi, 2011). A review of the literature revealed that a scarce number of studies have been conducted and published on the factors that influence the effectiveness of OHSAS 18001 in Iran. The study of Ghahramani and Summala (2015) showed that implementation of OHSAS 18001 and certification in Iran did not indicate a lower occupational injury rate during the certified years in manufacturing companies. Another study conducted by the author found that the implementation of OHSAS 18001 in Iran does not guarantee the improvement of safety climate in the companies (Ghahramani, 2016). However, the main objective of the current study was to identify the factors that influence the effectiveness of OHSAS 18001 based on the perspective of the participants in the adopting companies and the results are shown below.

\section{Method}

The present study was conducted in the West Azerbaijan province in Iran. The participants of the study consisted of sixteen managers, including fifteen male and one female. The managers worked in three OHSAS 18001-certified manufacturing companies. The companies were producers of chemical and goods used in construction. The number of employees who worked in the companies varied from 230 to 400 . Two of the companies were certified in 2002 and one of them became certified in 2007. The managers requited to the study based on their experience in the companies and on their familiarity with the management system. The preliminary assessment showed that the higher level managers of the companies participated in the OHSAS 18001 courses, managed the OHSAS 18001 practices in their units, and they were internal auditors of the management system. In addition, all OHS managers recruited to the study because of their direct roles in the management of OHS and the maintenance of OHSAS 18001 in the companies. The roles of the participants in the companies were as follows: representatives of the companies' senior managers in OHSAS $18001(n=3)$; OHS manager $(n=5)$; production managers $(\mathrm{n}=4)$; maintenance manager $(\mathrm{n}=3)$, and administrative manager $(n=1)$. The field of education of the interviewees was different: engineering $(n=15)$ and history $(n=1)$. The mean age of the participants was $41.56 \pm 6.61$ years, and their mean working experience was $15.44 \pm 5.80$ years.

The face-to-face semi-structured interviews with the participants were conducted in Azerbaijani Turkish. The main topic of the interviews was discovering the factors that can impact the effectiveness of OHSAS 18001. The interviewes had the same opening questions: "What factors from inside/outside your organization impact the maintenance and improvement of the system? What influencing factors can decrease or increase the effectiveness of OHSAS 18001 in the management of OHS? How can the effectiveness of OHSAS 18001 be improved in your company?" All interviews were anonymous and voluntary. The interviews were conducted by the author in the participants' offices. The interviews lasted from 20 to $70 \mathrm{~min}$. The interview-format was pretested in two pilot interviews, which were excluded from further analysis.

All interviews were recorded and transcribed verbatim. The line-by-line coding and content analysis were applied for analysis of the data. After reading the transcribed responses to the research questions for several times and applying the open coding (line-byline analysis), the data labeled and grouped into categories. The identified categories conceptualized further by specifying the relationship between the categories and integrating them into new form to generate new major categories (factors or themes). Then the factors were categorized into two main groups of inside and outside. Both manifest and latent content analyses were used to determine the presence of concepts in the raw data. The manifest content analysis was used for coding the data to identify the existing themes based on direct observations and direct quotes from the interviewees. Latent content analysis was employed for determining the underlying meaning of the data (Mullai and Paulsson, 2011; Smith, 2003). Then the grounded theory method was used for theoretical modeling of interviewees' perspectives about the factors that influenced the effectiveness of OHSAS 18001. Grounded theory is a suitable method to discover new or known areas from a fresh perspective. The resulting theory can offer insight, enhance understanding, and provide a meaningful guide to action. The basic action is a continuous comparison of theoretical constructs with raw data (Corbin and Strauss, 2008; Stave and Törner, 2007). 


\section{Results}

The analysis of the data indicated eleven categories of factors influencing the effectiveness of OHSAS 18001. These categories include management commitment, safety communication, employee involvement, integration, OHS training, safety culture, internal incentives, OHS enforcement, OHS authority' support, OHSAS 18001 auditing, and external incentives. The categories were divided into two groups of factors related to inside and outside the organization. These factors can impact the OHSAS 18001-adopting companies during maintenance and improvement of the requirements of the standard. The detailed analysis of the data generated a model that was grounded in the data (Fig. 1). The categories that emerged are presented in the following section.

\subsection{Factors inside the organization}

The participants expressed that the factors influencing the effectiveness of OHSAS 18001 inside the companies are management commitment, safety communication, employee involvement, integration, OHS training, safety culture, and internal incentives.

\subsection{Management commitment}

The participants emphasized that the most important influencing factor on the effectiveness of OHSAS 18001 was senior management commitment to safety. They were satisfied with their senior managers' commitment to safety during the implementation of the requirements of the OHSAS 18001 standard. However, the managers' commitment decreased after the implementation and led to the existence of a superficial OHSMS in the companies.

Without the true commitment of a senior manager to safety, nothing can improve the OHS performance in an OHSAS 18001certified company. The company performs OHS tasks in traditional ways and calls them as systematic. (Participant 13)

The participants stated that their top managers were not actively involved in the OHS and OHSAS 18001 practices. The specified tasks of the managers in OHSAS 18001 were entirely performed by their representatives in OHSAS. The interviewees also stated that individual engagement of senior managers in OHS and OHSAS 18001 practices can be a good way for improving the enthusiasm of employees to participate in the practices.

The practical meaning of the representative of the senior manager in our companies (in Iran) is that the senior managers do not have enough time for conducting their responsibilities in a management system; therefore, they appoint representatives to do their tasks in OHSMS. The managers assume that their management responsibilities in a certified company are separate from their responsibilities in a management system. (Participant 1)

The participants mentioned some situations that can be considered as evidence for the lack of senior managers' commitment to safety such as a lack of enough delegation of authorities to other managers, especially OHS managers; poor attitude of senior managers about OHSAS 18001 and safety; lack of priority to OHS compare with production; insufficient OHS knowledge of managers and employees; and inadequate financial support of the system. Senior managers did not ask other managers about their responsibilities in the system, and they did not try to determine the root causes of the existing shortcomings of OHSAS 18001 in the companies. Lack of top managers' commitment to the requirements of OHSAS 18001 was an obstacle to the effectiveness of OHSAS 18001 in improving the OHS performance.

A management representative in OHSAS 18001 receives power from the top manager. If the manager does not sincerely believe in the positive effect of the existence and development of the system, the management representative will not get enough authority to carry out his duties in the system. This situation can lead to an organization without a system for management of OHS. (Participant 1)

Top managers of Iranian organizations do not give enough priority to OHS compared with production. They look at OHS issues as minor issues in the companies. Creating a positive mindset

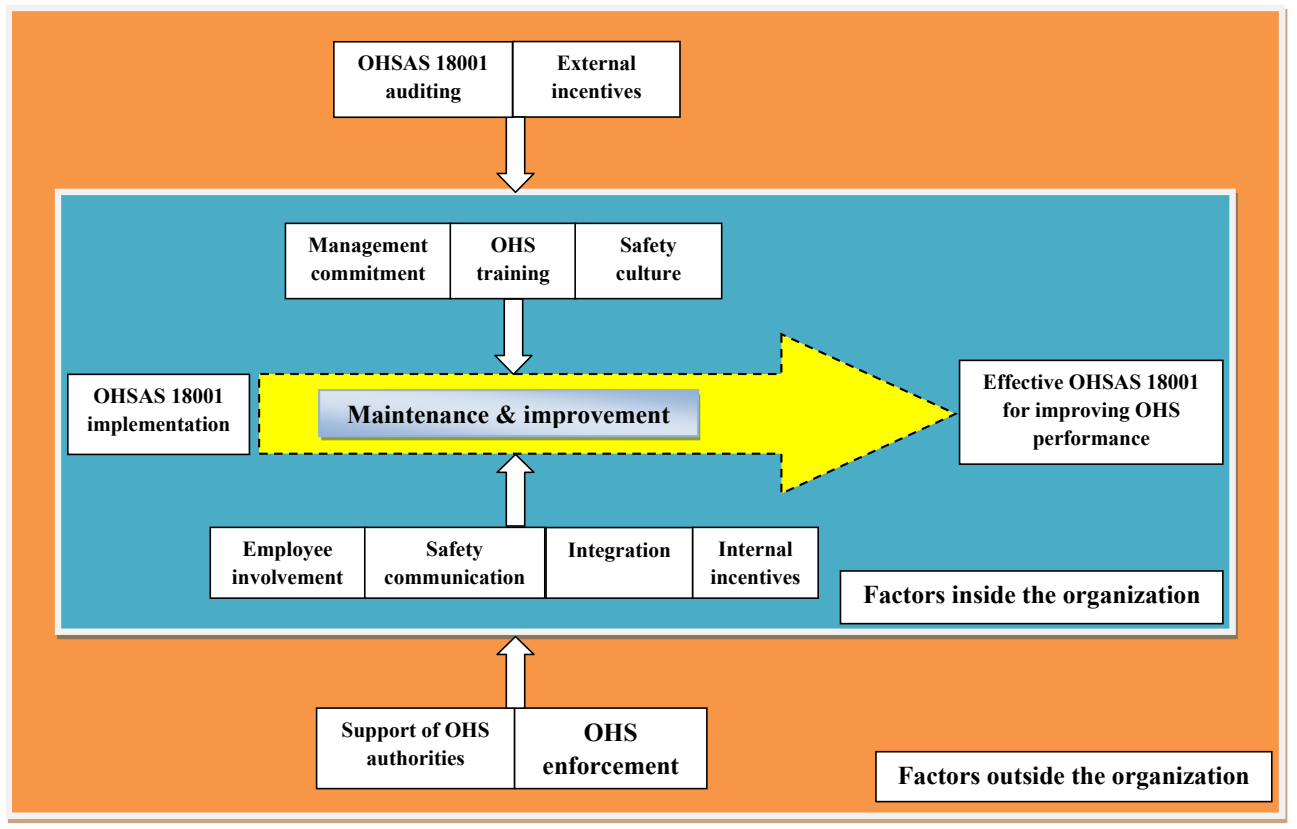

Fig. 1. Model of factors influencing the effectiveness of OHSAS 18001 
for the managers about the effect of OHS will be a more effective way to improve the OHS and OHSAS 18001. (Participant 12)

\subsection{Safety communication}

The interviewees pointed out that there was a lack of internal and external safety communication in the companies. The managers who conducted the majority of OHSAS 18001 practices did not communicate and consult with employees about OHS issues. The internal communication procedure did not consult with and involve employees in OHSAS 18001 practices, such as hazard identification and risk assessment, incident investigation, and proposal and application of control measures in their workstations. Thus, employees did not understand their responsibilities in OHSAS 18001. Employees were not interested in communicating with their managers and supervisors about OHS issues, because they feared dismissal from the companies due to the lack of job security.

There is lack of communication between managers and employees in our company. The managers did not communicate with the employees about OHS/OHSAS 18001 practices that they are responsible to conduct them and did not share OHS information with the employees. The employees did not communicate with their managers and supervisors about existing OHS problems and questions. (Participant 4)

\subsection{Employee involvement}

According to the participants, the employees of the companies were not actively involved in OHS/OHSAS 18001 practices. The employees did not engage in crucial practices to minimize the OHS risks in the companies such as hazard identification and risk assessment. The OHS/OHSAS 18001 practices were not seen as routine activities by employees, because they were mainly performed by OHS officers. The interviewees identified employee engagement as an important factor in the transformation of documentation (mechanical system) to practice (operational system). One participant noted, "The practices of OHSAS 18001 are usually seen as extra work; therefore, we cannot expect a successful system in our company" (Participant 3). Another participant added further:

The implementation of the requirements of the OHSAS 18001 in a company creates a huge amount of documentation. The sole way to transform the written OHSAS 18001 procedures and OHS instructions to practical habits for employees is use of them in practice. Therefore, without involvement of employees in OHSAS $18001 / \mathrm{OHS}$ practices, the requirements of the OHSAS 18001 standard remain on paper. (Participant 13)

The interviewees pointed out the main obstacles to employee participation in OHS/OHSAS 18001 practices. These factors included inadequate knowledge about OHS/OHSAS 18001, a lack of familiarity with the need for participation in OHS, shortage of information about the positive impacts of OHS participation, a poor attitude about OHS/OHSAS 18001, insufficient motivation, and scant job satisfaction.

\subsection{Integration}

Participants raised the lack of integration of OHSAS 18001 throughout the process and organizational frameworks as another important barrier to create an effective management system. The interviewees explained that the employees of the organizations considered OHS/OHSAS 18001 practices as the duties of safety managers. The OHSAS 18001 practices were assumed as extra tasks compared with their routine work activities. There was a common viewpoint that the practices of the OHSAS 18001 were separate from their traditional (routine) activities in the companies even some years after the certification.

In most of the Iranian organizations, the practices of management systems were employed in such a way that personnel of a certified company presume them as separate actions from their routine activities. Therefore, they perform the routine tasks of their jobs and are not interested in performing tasks involved with OHS/OHSAS 18001 practices. (Participant 3)

They mentioned the point that the OHS/OHSAS 18001practices were not performed on a daily basis. The companies mostly created the required documents a short time before external audits to prove the existence of required evidence to external auditors.

In our company, the majority of required documents was made one month before external audits. Unfortunately, OHS/OHSAS 18001 practices were not conducted daily because employees did not sincerely believe the importance of OHS and OHSAS for improving OHS performance. They also did not know why they had to carry out such practices. (Participant 14)

\subsection{OHS training}

Most of the participants emphasized that providing OHS training for employees could improve the effectiveness of OHSAS 18001. They stated that OHS training for employees is a continuous process. The use of different methods of training such as on/off the job training, provision of bulletins and videos, as well as displaying OHS posters can help employees to gain a better understanding of OHS. A lower level of workers' education was an obstacle to providing good safety training. In addition, the quality of safety training impacted the employees' attitude and behavior regarding OHS and OHSAS 18001. The interviewees stated that personnel of the companies usually know how they should carry out their responsibilities, but they do not know why they should perform them. One participant pointed out the role of high-quality safety training in the improvement of safety culture and its influence on the effectiveness of OHSAS 18001: "Personnel have to learn about why they conduct OHS/OHSAS 18001 practices. They should learn about the positive effects of OHS and OHSAS 18001 on their work and the company" (Participant 15).

\subsection{Safety culture}

The participants reported that the safety culture of an OHSAS 18001-adopting company influences the effectiveness of OHSAS 18001. Lack of practical efforts to improve the level of safety culture was an obstacle to the effectiveness of OHSAS 18001 and could lead to the existence of a paper-only system. They described how the companies can enhance the culture of safety.

The improvement of safety culture can be achieved through providing high-quality safety training and explanations of OHSAS 18001 procedures and instructions by all staff, especially the front-line employees. Otherwise, the system remains as a system only on paper and it is not used by employees in daily practice. (Participant 9) 
The interviewees pointed out that the efforts conducted by an OHSAS 18001-adopting company can increase the level of safety culture and help to achieve a satisfactory safety performance. They also affirmed that the certification of OHSAS 18001 and the existence of procedures/instructions cannot alone automatically lead to the improvement of OHS performance. One participant expressed an opinion about the need for a good safety culture in the companies:

It is impossible to observe and to supervise all employees every minute to ensure that they perform their practices in a safe manner. Therefore, it is essential to improve the level of safety culture to a point that every employee in a certified company thinks and behaves safely without the direct supervision of OHS officers; that is, they would be self-controlled. (Participant 7)

The participants stated that the implementation of OHSAS 18001 and certification by a Certifying Body (CB) are not difficult tasks. Whether managers and employees of a company be interested in implementing the requirements of the OHSAS18001 standard, they would eagerly conduct the OHSAS practices to achieve continuous improvement in OHS performance. This factor was stated as one of the important factors in the success of OHSAS 18001. More time is needed for the institutionalization of a positive safety culture and more efforts must be made by personnel to replace unsafe behaviors with safe ones. One participant suggested:

The best time for the implementation of the requirements of the OHSAS 18001 standard is the time that the personnel of a company sincerely believe in the importance of the management system, and have an interest in practically implementing its requirements. The most difficult part of the task occurs during the time that a certified company wants to perform and maintain the requirements of the OHSAS 18001 standard in practice. (Participant 6)

The interviewees explained that the companies have extended only a low-level of effort regarding safety culture. They asserted that it may result from societal attitudes that place a lower priority on OHS, the managers' poor attitudes toward safety, managers' insufficient knowledge of the OHS, and lack of enforcement of OHS legislation in the society.

\subsection{Internal incentives}

The participants expressed the opinion that the application of incentive programs can motivate the employees to perform their OHS/OHSAS 18001 tasks safely. It can also impact the effectiveness of OHSAS 18001.

Incentive programs could be used to encourage the employees who give more value to OHS issues and who have the best performance in OHS to persuade other employees to eagerly perform the OHS/OHSAS 18001 practices. Our experience shows that incentives can make employees more motivated to uphold OHS. (Participant 5)

\subsection{Factors outside the organization}

In addition to the factors within the adopting companies, other factors outside the companies were mentioned by the participants. They believed that the enforcement of OHS legislation by
OHS authorities (the Ministry of Cooperative Labor and Social Welfare, and the Ministry of Health and Medical Education) and their supports, the auditing conducted by CBs, and external incentives influence the effectiveness of OHSAS 18001 in the companies.

\subsection{OHS enforcement}

The participants reported that there is a lot of OHS legislation on paper in Iran. However, the problem is related to the enforcement policy regarding the implementation of the requirements of the OHS legislation. They believe that the implementation of the legislation can help to improve OHS and OHSAS status in the adopting companies. The interviewees were concerned with the OHS inspections that were conducted by the OHS authorities. Sometimes, non-scientific suggestions of OHS inspectors negatively affect the company, particularly the top managers. The participants pointed out that external organizations, such as the OHS authorities did not have any program for inspecting the quality of the implemented systems. They noted that the development of new programs for inspecting OHSAS 18001-adopting companies and for checking the quality of safety products such as personal protective equipment can help the OHSAS 18001-adopting companies to better maintain the system.

Enforcing OHS legislation and having a special program for conducting inspections in the OHSAS 18001-certified companies by the OHS authorities can be more useful for improving the effectiveness of OHSAS 18001 in the certified companies. (Participant 13)

OHS authorities, national standards organization or nongovernmental organizations (NGOs) must inspect and control the quality and appropriateness of OHSAS 18001 in certified companies. Such inspections can lead to increasing the quality of OHSAS 18001and preventing the existence of decorative systems in the certified companies. (Participant 2)

\subsection{OHS authorities' support}

Most of the respondents expressed that the OHS authorities' support for the OHSAS 18001-adopting companies can help to improve the system. These supports can include financial aid, OHS training, as well as providing guidance and consultation regarding OHS issues. The participants stated that the companies did not communicate enough or communicate with the OHS authorities about their OHS problems or questions. The participants also stressed that the OHS training that is prepared by the authorities should use mass media, especially TV.

The OHS authorities must properly guide and make suggestions to companies about their OHS problems and questions. The support of the authorities to persuade the companies can include providing OHS training courses or videos, creating a consultation center to respond to OHS questions, and suggesting tax discounts and financial support for conducting OHS programs. (Participant 8)

\subsection{Auditing}

Most of the participants criticized the quality of third-party audits. They mentioned that there is a high number of CBs in Iran that compete to audit OHSAS 18001-adopting companies. The CBs 
conduct superficial audits in the certified companies. They lack technical knowledge of their auditors' qualifications concerning industrial processes and other special OHS related issues in the companies being audited. Sometimes consulting companies have been re-organized to work as CB companies. In certain cases, the external auditors missed auditing important elements of the OHSAS 18001 standard, such as the role of top management and its commitment to OHS in the companies. The participants described some cases in which the auditors made proposals for adopting companies to conduct their OHS training courses or their OHS measurements with a specific company with which they had work relations. Considering these proposed actions, they did not conduct a serious audit of an adopting company.

$\mathrm{CB}$ companies compete to persuade more organizations to implement the OHSAS 18001 standard and to certify implemented systems. Then they also try to encourage their customers to extend their agreements with the certified companies for future audits. Such situations influence the quality of their audits. Sometimes, it leads them to conduct a superficial audit in OHSAS 18001-adopting companies to certify or extend the certification period. Moreover, only later did the certified companies learn the manner in which the OHSAS 18001auditors had conducted their audits. (Participant 10)

Iranian organizations usually implement the requirements of the OHSAS 18001 standard with the assistance of consulting companies. The companies help the organizations prepare their required procedures, instructions, and other documents based on the requirements of the standard. They also conduct training courses for the personnel of the organizations so that they are familiar with the requirements of the standard or OHS issues. Some of the companies changed their activities and became CBs some years after they had worked as a consulting company.

In some cases, consultants of a company for the implementation of the requirements of the OHSAS 18001 standard who knew the shortcomings of the implemented system come along with a CB's auditing team to conduct an audit. Thus, auditors would only report minor non-conformities of the system, not the major ones. For example, I expected some major non-conformities in some external audits of our company that could result in the cancellation of the OHSAS 18001 certificate, but that did not occur possibly due to these previous activities. (Participant 16)

\subsection{External incentives}

According to the participants, the existence of incentive programs for the OHSAS 18001-certified companies that experienced a better OHS performance in a specified period can be a good motivator for other companies to place more value on the OHS. It can considerably impact the effectiveness of the OHSAS 18001 to improve OHS performance in the adopting companies. The participants did also point out the usefulness of an incentive program for quality and environmental management systems in Iran.

When a company had a good level of improvements in its OHS performance as audited by an external company (i.e., NGOs), it was motivated to increase efforts to improve the OHS performance. Other companies also learned about their success and were encouraged to take part in such competitions. (Participant 11)

\section{Discussion}

The results of the present study indicated that senior management's commitment to safety, safety communication, employee involvement, integration, OHS training, safety culture, incentives, OHS enforcement, OHS authority support, and OHSAS 18001 auditing can inhibit or facilitate the effectiveness of OHSAS 18001 in the adopting companies. This study categorized these factors into two groups of internal and external factors using a grounded theory approach.

Based on the findings of the current study, the research showed that lack of a senior management commitment to safety was the main barrier to the effectiveness of OHSAS 18001. Many studies have emphasized the importance of senior manager commitment to safety (Arboleda et al., 2003; Cooper, 2000; Fernández-Muñiz et al., 2007; Vinodkumar and Bhasi, 2010). Vredenburgh (2002) stated that managers can manifest their commitment to safety through job-training programs, management participation in safety committees, consideration of safety in job design, and review of the pace of work. The findings of this study were also concerned with issues such as inadequate delegation of authority, lacking of OHS programs' support, failure to give priority to OHS, unsatisfactory feedback from other managers, and personnel's insufficient knowledge about OHS. The identified reason for the existence of these problems in the context of this study was the poor attitude of senior managers to OHS. The lack of the commitment can result in the existence of an unsuccessful and ineffective management system. It seems that the enhancement of senior management commitment to safety can lead to a successful OHSMS that continuously improves OHS performance in the companies.

The results of this study indicated that the OHS and OHSAS 18001 practices were mostly conducted by a limited number of managers, and the majority of employees did not participate in performing the practices. This finding shows that the inadequate participation of managers and employees in the OHS and OHSAS 18001 practices hindered the effectiveness of OHSAS 18001. This finding is in line with the studies of Lai et al. (2011) and Vinodkumar and Bhasi (2011) that reported employee involvement as a decisive factor in the improvement of safety performance. The resistance of personnel to participate in the OHS and OHSAS 18001 practices could be connected with the insufficient OHS and OHSAS 18001 knowledge, poor OHS attitude, job dissatisfaction, a lack of a motivational program for participation, a lack of communication and consultation about OHS issues in their workstations, and a lack of commitment to safety. The manner that the companies employed for the implementation of the requirements of the OHSAS 18001 standard showed that they were in a hurry to implement all the requirements before third-party audits were conducted with the help of the consulting companies; this may be related to the employees' lack of engagement. The resistance of employees may result from the fact that they are less empowered. The study of Cohen and Cleveland (1983) found that empowering employees provides them with authority, responsibility, and accountability for required decisions and ensures that both employees and managers are involved in setting goals and objectives.

The lack of adequate OHS training was found as an obstacle to the effectiveness of OHSAS 18001 in the companies. The participants emphasized the need for OHS training, especially regarding the positive effects of OHS and the systematic management of OHS. They felt that employees should understand why they need to perform the OHS/OHSAS 18001 practices. These findings are in line with the study of Teixeira and Sampaio (2013), based on the previous studies, which confirmed that the lack of confidence in a food safety management system resulted from a lack of information and insufficient support and guidance. Providing high-quality OHS 
training can improve the employees' abilities to perform their duties safely. It can also enhance the productivity of the companies by positively affecting employees' behavior and decreasing the number of occupational accidents and illnesses.

The existence of a poor safety culture in the OHSAS 18001adopting companies was identified as an obstacle to the effectiveness of OHSAS 18001. Prior studies have reported that the implementation of OHSAS 18001 is not enough to create an effective system, and the adopting companies should work harder to improve the safety culture (Gordon et al., 2007; Granerud and Rocha, 2011). Therefore, the OHSAS 18001-adopting companies should improve the safety culture along with the implement of a mechanical management system and after certification. It is important to note that the creation of a significant modification in the safety culture requires more time. The adopting companies and those that plan to adopt the requirements of the OHSAS 18001 standard should not be in a hurry for implementation of the requirements of the standard and certification by a CB. The companies should train their employees and involve them in OHS/ OHSAS 18001 practices until the practices are implemented and work is conducted safely on a daily basis.

The insufficient application of incentive programs to encourage companies and employees was also recognized as a factor that affects the effectiveness of OHSAS 18001 from inside and outside the companies. Ai Lin Teo et al. (2005) found that incentives and rewards are good management practices for working safely that can lead to a strong safety culture. The finding of the current study is mainly concerned with a lack of incentive program within the companies and a lack of incentive program exists on the outside. A well-designed incentive program that offers recognition can help to modify the behavior of employees (Vredenburgh, 2002). Therefore, using suitable incentive programs inside and outside the companies can help to increase the interest of employees in more participation in OHS/OHSAS practices and the companies to achieve an optimum OHS performance.

The lack of OHS enforcement and OHS authorities' support were identified as external factors that impact the effectiveness of OHSAS 18001. Earlier studies indicated the importance of OHS enforcement on the improvement of safety performance. Effective enforcement is vital to the successful implementation of OHS legislation (Gunningham and Sinclair, 2007). Routine inspections without any form of enforcement apparently have no injuryreducing effects (Gunningham and Sinclair, 2007). The objective of OHS inspections should not only be to identify clear hazards, but should also be to provide information and advice for employees regarding existing OHS problems; this information should be transmitted both face-to-face and in writing. OHS inspections must have a thorough understanding of OHS hazards and appointee control measures associated with the activities of employees due to the unique characteristics of any workplace. The lack of experience and relevant training of the OHS inspectors was identified as a significant obstacle to effective enforcement (Gunningham, 2005). Therefore, the application of an enforcement policy to ensure the successful implementation of OHS legislations may help the certified companies to improve their OHS performance. Perhaps considering other requirements of the OHSAS 18001 standard by inspectors of the OHS authorities during their inspections would also be useful. Providing the specific training about the OHS of the companies and OHSAS 18001 can also improve the qualifications of the inspectors.

The present study also indicated that third-party auditing of OHSAS 18001 and inspections conducted by OHS authorities are other important factors that affect the provision of an effective system for the management of OHS in the companies. Safety inspections and safety audits are the two most important tools used to measure the success of an OHSMS and to ensure the quality of safety management (Cooper and Phillips, 2004; Salazar, 1989). The identified shortcomings of the OHSAS 18001 auditing process in the present study included insufficient lead time in providing necessary documents before auditing, and the auditors' lack of a process and OHS knowledge in the audited organization. There was a suggestion to conduct training courses and OHS measurements in adopting companies by the CBs, and possible prior relationships between auditors and the OHSAS 18001-adopting companies. There was a lack of employee participation in the auditing process, as they were missing the important elements of the management standard to check in auditing. These failures that have been identified previously by other researchers can significantly impact the auditing of OHSAS 18001 in adopting companies (Tackett, 2004; Blewett and O'Keeffe, 2011). The utilization of a policy by the accreditation bodies for checking the quality of OHSAS 18001 audits conducted by CBs could identify the shortcomings of the audit process and help to increase their quality. The additional checking by OHS authorities in their inspections or NGOs can help to create creating a healthy and safe workplace and to identify the auditing failures and facilitate the enhancement of the quality of third-party audits.

Integration of OHSAS 18001 throughout the process and organizational frameworks could improve the performance of OHS in reality, not on paper. Organizational actions such as involvement of employees in OHS/OHSAS 18001 practices, OHS training, and enhancement of safety culture could facilitate this integration (Badri et al., 2012; Yazdani et al., 2015). Such integration could result in continuous improvement of OHS and OHSAS 18001 performance, and sustainable prevention of occupational injuries, illnesses and accidents.

The current study identified the lack of management commitment, employee involvement, safety communication, integration, poor safety culture, incentives, safety training as influencing factors within the companies to the improvement of OHAS 18001. These findings clearly indicate the lack of practices to operationalize the requirements of the OHSAS 18001 standard and the presence of mechanical management systems in the companies. Considering the hypotheses discussed by Frick (2014) about the OHSMS, it can be inferred that paper tiger systems existed in the studied organizations. These findings suggest that the implementation of the requirements of the OHSAS 18001 standard would not enable enough changes in the companies to achieve the aims of the standard.

Hopefully, the model developed in the current study can contribute to a better understanding of factors influencing the maintenance and improvement of OHSAS 18001 in the adopting companies. It can also provide useful information for the OHSAS 18001-adopting organizations, OHS authorities, and CBs to consider in the improvement of the management system in the adopting companies.

\section{Conclusions}

The current study describes the major barriers to and facilitators of the effectiveness of OHSAS 18001 in the adopting companies. Based on the study findings, the senior managers' commitment to safety and their support of employees to participate in OHS and OHSAS 18001 practices can facilitate the improvement of OHSAS 18001 in the companies. Providing training for the employees about the OHS issues and OHSAS 18001 so that they understand why they should become involved in OHS/OHSAS 18001 practices may positively impact the management system. If employees understand the importance of OHS/OHSAS 18001 and the positive effects they can have on their companies, OHS performance would 
be improved. The development of a new inspection program with more emphasis on the enforcement of OHS legislation by the OHS authorities to inspect the quality of OHSAS 18001 can help the companies to improve the effectiveness of their systems for better management of OHS. The application of an enforced policy by accreditation bodies to check the third-party auditing process could identify the shortcomings of the OHSAS 18001 audits and increase the quality of auditing. The use of an external incentive program and communication procedure could motivate the companies to adopt the requirements of the OHS legislation. The use of an internal incentive program and communication procedure could encourage the employees to perform the OHS/OHSAS 18001 practices and to share OHS information. These efforts may help the companies in the creation of a good safety culture and deepen the management system, from the superior layer of the company (i.e., managers) to the deeper layer (i.e., workers), in addition to transforming the paper system to an effective management system. All mentioned efforts may help a better integration of OHSAS 18001 in the process and organizational frameworks of the companies. Because there is a scarce number of studies about the effectiveness of OHSAS 18001 in the adopting companies, more research is needed in this field. More research to identify applicable evidence about the developed model should also be conducted.

\section{References}

Ai Lin Teo, E., Yean Yng Ling, F., Sern Yau Ong, D., 2005. Fostering safe work behaviour in workers at construction sites. Eng. Constr. Archit. Manag. 12, 410-422.

Arboleda, A., Morrow, P.C., Crum, M.R., Shelley, M.C., 2003. Management practices as antecedents of safety culture within the trucking industry: similarities and differences by hierarchical level. J. Saf. Res. 34, 189-197.

Badri, A., Gbodossou, A., Nadeau, S., 2012. Occupational health and safety risks: towards the integration into project management. Saf. Sci. 50, 190-198.

Blewett, V., O'Keeffe, V., 2011. Weighing the pig never made it heavier: auditing OHS, social auditing as verification of process in Australia. Saf. Sci. 49, 1014-1021.

Bluff, E., 2003. Systematic Management of Occupational Health and Safety (National research centre for occupational health and safety regulation).

BSI., 2007. OHSAS 18001 Occupational health and safety management systems. requirements.

Chang, J.I., Liang, C.L., 2009. Performance evaluation of process safety management systems of paint manufacturing facilities. J. Loss Prev. Process Ind. 22, 398-402.

Chen, C.Y., Wu, G.S., Chuang, K.J., Ma, C.M., 2009. A comparative analysis of the factors affecting the implementation of occupational health and safety management systems in the printed circuit board industry in Taiwan. J. Loss Prev. Process Ind. 22, 210-215.

Cohen, H.H., Cleveland, R.J., 1983. Safety program practices in record-holding plants. Prof. Saf. 28, 26-33.

Cooper, M.D., 2000. Towards a model of safety culture. Saf. Sci. 36, 111-136.

Cooper, M.D., Phillips, R.A., 2004. Exploratory analysis of the safety climate and safety behavior relationship. J. Saf. Res. 35, 497-512.

Corbin, J., Strauss, A., 2008. Basics of Qualitative Research: Techniques and Procedures for Developing Grounded Theory. Sage.

Fernández-Muñiz, B., Montes-Peón, J.M., Vázquez-Ordás, C.J., 2007. Safety management system: development and validation of a multidimensional scale. J. Loss Prev. Process Ind. 20, 52-68.

Fernández-Muñiz, B., Montes-Peón, J.M., Vázquez-Ordás, C.J., 2009. Relation between occupational safety management and firm performance. Saf. Sci. 47, 980-991.

Fernández-Muñiz, B., Montes-Peón, J.M., Vázquez-Ordás, C.J., 2012a. Occupational risk management under the OHSAS 18001 standard: analysis of perceptions and attitudes of certified firms. J. Clean. Prod. 24, 36-47.

Fernández-Muñiz, B., Montes-Peón, J.M., Vázquez-Ordás, C.J., 2012b. Safety climate in OHSAS 18001-certified organisations: antecedents and consequences of safety behaviour. Accid. Anal. Prev. 45, 745-758.

Frick, K., 2011. Worker influence on voluntary OHS management systems-a review of its ends and means. Saf. Sci. 49, 974-987.

Frick, K., 2014. The 50/50 implementation of Sweden's mandatory systematic work environment management. Policy Pract. Health Saf. 23-46.

Gallagher, C., 2000. Occupational Health and Safety Management Systems: System Types and Effectiveness. Deakin University.

Gill, G.K., Shergill, G.S., 2004. Perceptions of safety management and safety culture in the aviation industry in New Zealand. J. Air Transp. Manag. 10, 231-237.

Goh, Y.M., Chua, D., 2013. Neural network analysis of construction safety management systems: a case study in Singapore. Constr. Manag. Econ. 31, 460-470.

Ghahramani, A., Summala, H., 2015. A study of the effect of OHSAS 18001 on the occupational injury rate in Iran. Int. J. Inj. Control Saf. Promot. http://dx.doi.org 10.1080/17457300.2015.1088038.

Ghahramani, A., 2016. An investigation of safety climate in OHSAS 18001-certified and non-certified organizations. Int. J. Occup. Saf. Ergon. http://dx.doi.org/ 10.1080/10803548.2016.1155803.

Gordon, R., Kirwan, B., Perrin, E., 2007. Measuring safety culture in a research and development centre: a comparison of two methods in the air traffic management domain. Saf. Sci. 45, 669-695.

Granerud, R.L., Rocha, R.S., 2011. Organisational learning and continuous improvement of health and safety in certified manufacturers. Saf. Sci. 49, 1030-1039.

Gunningham, N., 2005. Safety regulation and the mining inspectorate-lessons from western Australia. J. Occup. Health Safety-ANZ 21, 299-309.

Gunningham, N., Sinclair, D., 2007. Multiple OHS Inspection Tools: Balancing Deterrence and Compliance in the Mining Sector. National research centre for OHS regulation, Canberra.

Hofmann, D.A., Jacobs, R., Landy, F., 1995. High reliability process industries: individual, micro, and macro organizational influences on safety performance. J. Saf Res. 26, 131-149.

Kjellén, U., 2012. Managing safety in hydropower projects in emerging market$\mathrm{s}$-experiences in developing from a reactive to a proactive approach. Saf. Sci. 50, 1941-1951.

Lai, D.N., Liu, M., Ling, F.Y., 2011. A comparative study on adopting human resource practices for safety management on construction projects in the United States and Singapore. Int. J. Proj. Manag. 29, 1018-1032.

LaMontagne, A., Barbeau, E., Youngstrom, R., Lewiton, M., Stoddard, A., McLellan, D. Wallace, L.M., Sorensen, G., 2004. Assessing and intervening on OSH programmes: effectiveness evaluation of the Wellworks-2 intervention in 15 manufacturing worksites. Occup. Environ. Med. 61, 651-660.

Mullai, A., Paulsson, U., 2011. A grounded theory model for analysis of marine accidents. Accid. Anal. Prev. 43, 1590-1603.

Robson, L.S., Clarke, J.A., Cullen, K., Bielecky, A., Severin, C., Bigelow, P.L., Irvin, E. Culyer, A., Mahood, Q., 2007. The effectiveness of occupational health and safety management system interventions: a systematic review. Saf. Sci. 45, 329-353.

Salazar, N., 1989. Applying the deming philosophy to the safety system. Prof. Saf. 34, 22-27.

Smith, K.P., 2003. A Qualitative Study of Deterrence and Deviance in a Group of Recidivist Drink Drivers. University of Canberra.

Stave, C., Törner, M., 2007. Exploring the organisational preconditions for occupational accidents in food industry: a qualitative approach. Saf. Sci. 45 (3), 355-371.

Tackett, J., 2004. Sarbanes-Oxley and audit failure: a critical examination. Manag. Audit. J. 19, 340-350.

Teixeira, S., Sampaio, P., 2013. Food safety management system implementation and certification: survey results. Total Qual. Manag. Bus. Excell. 24, 275-293.

Vinodkumar, M., Bhasi, M., 2010. Safety management practices and safety behaviour: assessing the mediating role of safety knowledge and motivation. Accid. Anal. Prev. 42, 2082-2093.

Vinodkumar, M., Bhasi, M., 2011. A study on the impact of management system certification on safety management. Saf. Sci. 49, 498-507.

Vredenburgh, A.G., 2002. Organizational safety: which management practices are most effective in reducing employee injury rates? J. Saf. Res. 33, 259-276.

Yazdani, A., Neumann, P., Imbeau, D., Bigelow, P., Pagell, M., Wells, R., 2015. Prevention of musculoskeletal disorders within management systems: a scoping review of practices, approaches, and techniques. Appl. Ergon. 51, 255-262.

Zachariassen, S., Knudsen, S., 2002. Systematic approach to occupational health and safety in the engineering phase of offshore development projects, experiences from the Norwegian petroleum activity. Soc. Pet. Eng. Inc. SPE 73881, 246-249.

Zohar, D., Luria, G., 2003. The use of supervisory practices as leverage to improve safety behavior: a cross-level intervention model. J. Saf. Res. 34, 567-577. 